\title{
The impact of immunization on the association between poverty and child survival: Evidence from Kassena-Nankana District of northern Ghana
}

\author{
Ayaga A. Bawah \\ James F. Phillips \\ Population Council \\ Martin Adjuik \\ Maya Vaughan-Smith \\ Population Council \\ Bruce MacLeod
}

See next page for additional authors

Follow this and additional works at: https://knowledgecommons.popcouncil.org/departments_sbsr-pgy

Part of the Demography, Population, and Ecology Commons, Family, Life Course, and Society Commons, Inequality and Stratification Commons, International Public Health Commons, Maternal and Child Health Commons, Medicine and Health Commons, and the Women's Health Commons How does access to this work benefit you? Let us know!

\section{Recommended Citation}

Bawah, Ayaga A., James F. Phillips, Martin Adjuik, Maya Vaughan-Smith, Bruce MacLeod, and Fred N. Binka. 2006. "The impact of immunization on the association between poverty and child survival: Evidence from Kassena-Nankana District of northern Ghana," Policy Research Division Working Paper no. 218. New York: Population Council. 


\section{Authors}

Ayaga A. Bawah, James F. Phillips, Martin Adjuik, Maya Vaughan-Smith, Bruce MacLeod, and Fred N.

Binka 


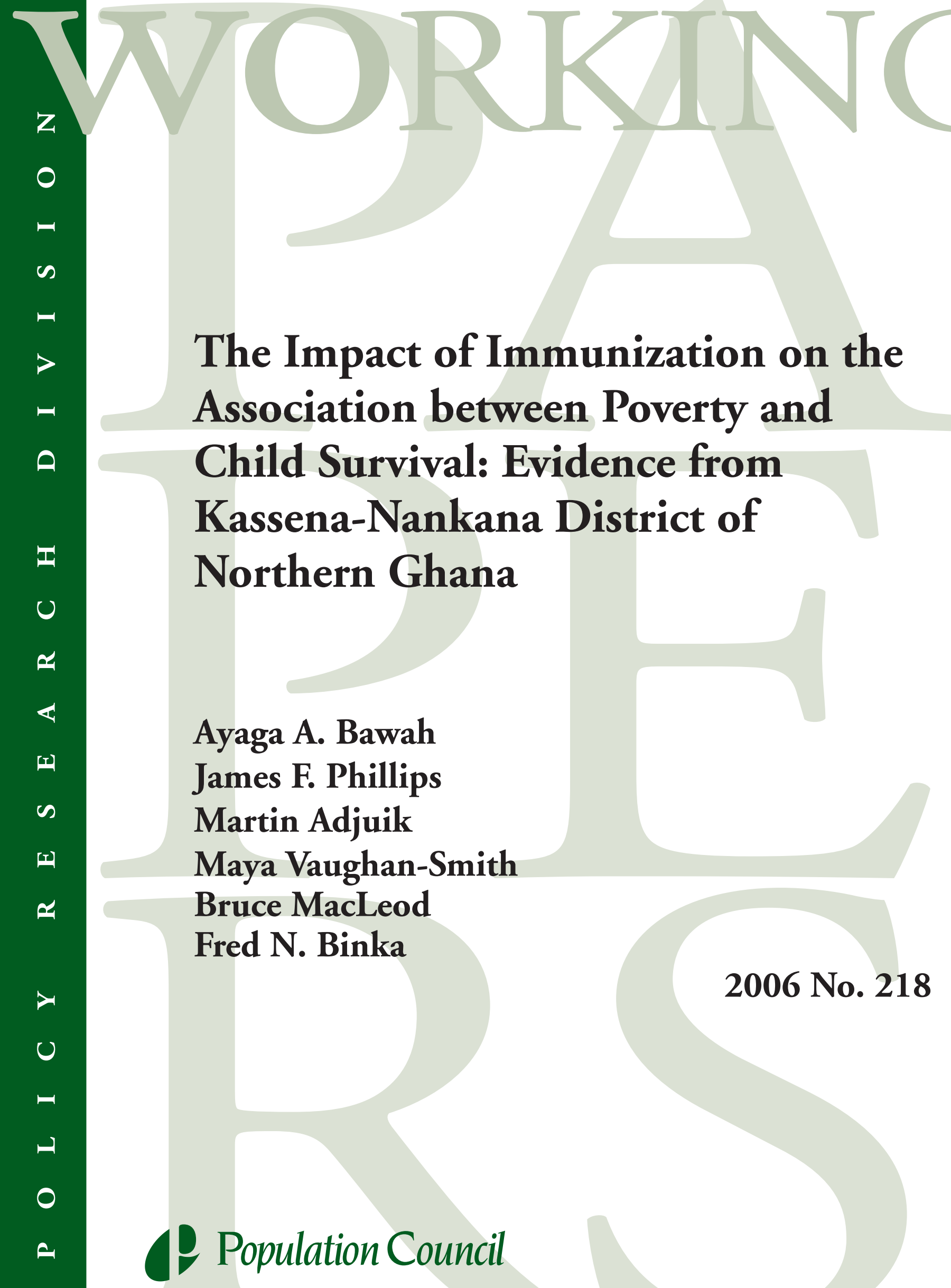




\section{(P) Population Council}

One Dag Hammarskjold Plaza

New York, New York 10017 USA

www.popcouncil.org

pubinfo@popcouncil.org

This material may not be reproduced without written permission from the authors. For a list of Policy Research Division Working Papers, including those that are currently available for downloading in PDF format, see www.popcouncil.org/publications/wp/prd/rdwplist.html.

ISSN: $1554-8538$

(C) 2006 The Population Council, Inc. 


\title{
The Impact of Immunization on the Association between Poverty and Child Survival: Evidence from Kassena-Nankana District of Northern Ghana
}

\author{
Ayaga A. Bawah \\ James F. Phillips \\ Martin Adjuik \\ Maya Vaughan-Smith \\ Bruce MacLeod \\ Fred N. Binka
}

\begin{abstract}
Ayaga A. Bawah is Research Scientist, INDEPTH Network, Accra, Ghana. James F. Phillips is Senior Associate, Population Council. Martin Adjuik is Scientist, Navrongo Health Research Centre, Ghana Health Service, Upper East Region, Ghana. Maya Vaughan-Smith is Research Assistant, Population Council. Bruce MacLeod is Associate Professor, Department of Computer Science, University of Southern Maine, Portland. Fred N. Binka is Professor, School of Public Health, University of Ghana, Legon. We acknowledge the staff of the Navrongo Demographic Surveillance System who worked tirelessly to collect the data and the director, Abraham Hodgson, for granting us permission to use the data.
\end{abstract}




\begin{abstract}
Research conducted in Africa has demonstrated consistently that parental poverty and low educational attainment adversely affect child survival. Research conducted elsewhere has demonstrated that low-cost vaccines against preventable diseases reduce childhood mortality. Therefore, the extension of vaccination to impoverished populations is widely assumed to diminish equity effects. Recent evidence that childhood mortality is increasing in many countries where vaccination programs are active challenges this assumption. This paper marshals data from accurate and complete immunization records and survival histories for 18,368 children younger than five in a rural northern Ghanaian population that is generally impoverished, but where family wealth and parental educational differentials exist nonetheless. Time-conditional Weibull hazard models are estimated to test the hypothesis that childhood immunization offsets the detrimental effects of poverty and low educational attainment. Findings show that the adverse effects of poverty disappear and that the effects of educational attainment are reduced in survival models that control for immunization status. This finding lends empirical support to policies that promote immunization as a strategic component of poverty-reduction programs.
\end{abstract}


Research throughout Africa has shown that parental poverty and low educational attainment are adversely associated with the survival of children (Muhuri 1995; Montgomery et al. 2000; Filmer and Pritchett 2001; Gwatkin 2002a; Bawah and Zuberi 2005; Debpuur et al. 2005; Kahn et al. 2005; Nathan et al. 2005). Extensive scientific evidence also demonstrates that low-cost vaccines are effective in reducing childhood mortality (World Bank 1993; Nyarko et al. 2001; Victora et al. 2003; GAVI 2005; Levine et al. 2005; United Nations 2006). Therefore, the adverse child-survival effects of poverty and low parental educational are widely assumed to be offset by the promotion of comprehensive childhood immunization (World Bank 1993; Sachs and MacArthur 2005), and immunization has become a critical component of policies that aim to address health inequity (Gwatkin et al. 2005). Nonetheless, an examination of the impact of immunization on the association between poverty and child survival should be appraised directly. Health conditions, particularly for children, are worsening throughout sub-Saharan Africa despite the widespread promotion of immunization in the region (Timaeus 1997a, 1997b, and 1999; Ahmad et al. 2000; Black et al. 2003; Hill 1993; United Nations 2005a and 2005b; World Bank 2005). This finding challenges the assumption that immunization offsets the effects of poverty. Extrapolations of trends suggest that the Millennium Development Goals (MDGs) for child survival are not being achieved in the region (Sahn and Stifel 2003). Moreover, assessing the precise relationship between immunization and poverty alleviation is constrained by the difficulty in marshaling accurate and complete immunization data in conjunction with longitudinal survival observation of large cohorts of children (Fine 2005; Aaby and Jensen 2005. For this reason, evidence from aggregate data that mortality declines are stagnating cannot be linked with information on immunization coverage. The role of immunization coverage in the stagnation of trends is unknown.

The consensus remains that achieving the United Nations Millennium Development Goal of reducing child mortality by two-thirds over the 1990-2015 period will require widespread immunization coverage against infection by preventable diseases (including tuberculosis, pertussis, tetanus, polio, and measles). Controversy persists, however, about the importance of focusing policy on the promotion of specific health interventions versus systems approaches to developing packages of essential services. Achieving the child-survival MDG may require simultaneous attention to a range of prevalent sources of childhood morbidity, such as diarrheal diseases, malaria, acute respiratory infections, and malnutrition. These efforts may interact in ways that prevent immunization from having its intended survival effects. Some proponents of health- systems reform and sector-wide community health services argue that policies focused on promoting specific health interventions are tantamount to abandoning global social and economic health-equity goals (Magnussen et al. 2004). The child-survival effects of maternal educational attainment have been demonstrated for nearly three decades (Caldwell 1979), but questions persist about the efficacy of such focused health interventions as immunization in attenuating these effects (Desai and Alva 1998). Addressing debate about the role of childhood immunization in mitigating the social and economic determinants of mortality remains a critical issue for health policy in Africa. This paper examines the empirical basis for the MDG focus on immunization by testing the hypothesis that immunization offsets the detrimental effects of poverty and low educational attainment in an impoverished rural setting of northern Ghana. 
International focus on expanding immunization coverage spans more than two decades of global commitment and action. Adopting immunization as one of its child-survival strategies, UNICEF joined with the World Health Organization in 1986 in pioneering a worldwide global campaign promoting immunization through the provision of technical, financial, and logistical support to developing countries (WHO/AFRO 1994). Subsequently, the United States Agency for International Development joined this partnership with the goal of promoting universal access to immunization against preventable diseases, an effort that was recently joined by the Global Alliance for Vaccines and Immunization (GAVI). As a result of these commitments, most sub-Saharan African countries now incorporate free childhood immunization services in national health-care systems, and many developing countries have registered substantial success in improving immunization coverage. A recent UN (2005c) report estimates that at current levels and trends, governments would require at least 90 percent coverage in immunization in their countries to meet the child-survival MDG by 2015. Coverage levels in many countries in subSaharan Africa are far below the 90 percent threshold, however. Ghana exemplifies this problem. Although national coverage rates in Ghana are higher than in other West African countries, with most of the vaccinations exceeding 80 percent coverage, pronounced differences exist within the country by region and district (GSS et al. 2004).

Poverty has also consistently been shown to be associated with childhood mortality. Several studies have demonstrated that the burden of disease is highest among the poorest segments of populations (Wagstaff 2000; Kiros and Hogan 2001; Gwatkin 2002b). The poor are unable to afford curative care, are unaware of the importance of preventive care, and are at greater risk because of their high levels of malnutrition or living arrangements that lower their resistance to infectious diseases (Gadomski et al. 2001). Moreover, the poor and less-educated are less likely than those who are better off to comply with a medical regimen, enhancing their risk of developing antibiotic resistance (Gwatkin et al. 2005).

Although immunization, maternal educational attainment, and poverty are known to covary in many settings, their various independent and joint effects in Africa remain unknown (Attaran 2005). Immunization may offset the effects of poverty by reducing the time and resources parents spend on nursing sick children and thus may divert resources that would otherwise be used in caring for sick children. Immunization programs may provide a basis for addressing health inequity, because the provision of mass immunization does not discriminate between children of the poor and the better-off or the educated and the less-educated. This paper examines data from a district where questions can be addressed about the effect of immunization on the association between poverty and maternal educational attainment and child survival.

\section{The SETTING}

This study is derived from a longitudinal observation of the population of KassenaNankana District in northern Ghana, which is ideally suited for such an investigation. In this setting, the Navrongo Health Research Centre (NHRC) has completed more than a decade of longitudinal demographic surveillance of the entire population of the district. Immunization records are also prospectively compiled and linkable to survival histories of children younger than five. Kassena-Nankana District lies within the Guinea Savannah woodland zone of northern 
Ghana, where social and economic conditions are among the worst in the country. The district covers a land area of 1,675 square kilometers and lies at the border with Burkina Faso in the Upper East region (see map, Figure 1). Geographic isolation and social deprivation make the district one of the poorest in Ghana. The district is also one of the most arid, with a long dry season punctuated by only three months of rainfall and average monthly temperatures ranging between 20 and 40 degrees Celsius. Thus, the district typifies the harsh environmental conditions of Sahelian West Africa and the challenging circumstances for development in Ghana's northern regions. Although limited irrigation is practiced during the dry season, subsistence agriculture remains the mainstay of the economy.

Demographic and health conditions in Kassena-Nankana District reflect the adverse ecological and economic circumstances of the area. Prior to the health interventions of the Navrongo Centre, the district had one of the highest mortality levels in Ghana (VAST Study Team 1993). Although health conditions were unfavorable in the early 1990s, results from the most recent Ghana Demographic and Health Survey (GDHS) show that both infant and child mortality have declined in the Upper East region in recent years, while conditions have worsened in all other regions of the country (GSS et al. 2004). Fertility and mortality declines are particularly pronounced in Kassena-Nankana District (Phillips et al. forthcoming). Infant mortality declined from 129 deaths per 1,000 live births in 1995 to 85 in 2003, representing a 34 percent decrease, while mortality of children younger than five declined from about 147 to 83 deaths, representing a 44 percent decrease over the period (Binka et al. forthcoming). Although childhood mortality remains high, and infectious diseases are the predominant cause of deaths in the district, all causes of childhood illness have declined, including malaria, diarrheal diseases, acute respiratory infections, and immunizable diseases (Adjuik et al. 2006).

The social, economic, and geographic circumstances of northern Ghana also constrain the delivery of social and health services. The mobility of health services is restricted by the lack of resources for facilities, supplies, fuel, and equipment. Services at stationary facilities in the district are underused because the cost of travel and of services and medicines at clinics is prohibitive for most rural families. Consequently, parents confronting their children's illnesses resort either to traditional medicine or self-medication, purchasing medicines from untrained village hawkers. The innovations derived from research conducted at the Navrongo Health Research Centre have improved the health situation in Kassena-Nankana District over the past several years, however.

\section{THE DATA}

Data used for the analysis presented in this paper are drawn from the Navrongo Demographic Surveillance System (NDSS), a system of continuous assessment of demographic dynamics in Kassena-Nankana District (Binka et al. 1999). In 1993, the entire district's population was enumerated and registered in a relational database. At quarterly intervals since July 1993, field-workers visit all dwelling units in the district to update the information obtained in previous rounds regarding changes in household relationships, births, deaths, in- and outmigration, and pregnancies occurring in each 90-day period. Annual updates of immunization status and educational attainment and indicators of socioeconomic status are linked to the 
demographic register. Data checking and correction are maintained prospectively, allowing for an accurate appraisal of population size and composition, fertility, mortality, and migration.

Data for this paper include information about all 17,967 children born between 1 January 1998 and 31 December 2004. Aggregate mortality rates exhibit childhood-mortality regimes that are typical of Sahelian West Africa (see Figure 2). Risks during the first month of life are double the mortality rates in the postneonatal period. Monthly mortality rates decline monotonically as children age beyond infancy.

In Table 1, mean cumulative immunization coverage rates are shown for each of eight vaccines by age of child for a cohort of Kassena-Nankana children observed over the 1998-2004 period. Except for measles, the proportion of children covered by the various vaccines is around 75 percent or more after the first year. The coverage of measles vaccination is low in the first year of life because measles immunization is usually provided at nine months of age, and most mothers fail to follow the nine-months regimen strictly, waiting until prompted by health workers after their child has passed infancy.

Figure 3 shows the immunization status of all children with respect to all vaccines combined as age advances through the months of infancy. Three categories of children are shown: those not immunized (none), those partially immunized (partial), and those fully immunized (full). WHO guidelines stipulate that a fully immunized child must have received one dose of bacillus Calmette-Guerin (BCG) vaccine (at birth), three doses of poliomyelitis vaccine (at the sixth, tenth, and $14^{\text {th }}$ week after birth), three doses of diphtheria, pertussis, and tetanus (DPT) (at the sixth, tenth and $14^{\text {th }}$ week after birth), and measles vaccine at nine months. Thus, the WHO guidelines for "partial" versus "full" immunization status stipulate that status is to be determined at an age when all vaccinations combined could have an effect rather than at the time that each immunization is administered. Although this definition is useful for the interpretation of cross-sectional survey data, prospectively observed children dying before the time that vaccinations are due are, by definition, "partially immunized" or "not immunized" at the time of death, depending upon whether any vaccine was provided by the time of death (WHO Department of Vaccines and Biologicals 2001).

Models for the analysis presented here are based on the status of each child at the time of last observation with respect to the WHO definition. The observed timing of immunization relative to the WHO-prescribed timing of immunization is illustrated in Figure 3. Although completion of appropriately timed immunization increases monotonically with age, reaching more than two-thirds of all children past infancy, partial coverage of immunization varies as the timing of new steps in the desired regimen are reached. As the figure shows, incomplete immunization increases after the postneonatal period and remains steady throughout the postneonatal months of infancy, even though full coverage advances with increasing age. Because children are often immunized late against measles, a marked increase in incomplete coverage is evident at month nine that declines after infancy.

\section{THE MODEL}

The analysis estimates parameters of the proportional hazards model, assuming that the hazard rate for childhood mortality is the product of a baseline failure rate, $h_{0}(t)$, which is a 
function of time only, and a positive function $g(x, A)$, independent of time, which incorporates the effects of a vector $X$ comprised of covariates, such as immunization vaccine, mother's characteristics (age and educational attainment), and an index of poverty as estimated by the method of principal components. The conditional hazard is given by

$$
h(t / \underline{X})=h_{o}(t) \cdot g(\underline{X}, \underline{A})
$$

where

$\underline{X}$ is a row vector consisting of the covariates

$$
\underline{X}=\left(x_{l}, \mathrm{x}_{2}, \ldots . \mathrm{x}_{\mathrm{m}}\right)
$$

$\underline{A}$ is a column vector consisting of the effects of unknown parameters of the model, compounded over $T$ units of time

$$
\underline{A}=\left(a_{l}, a_{2}, \ldots . \mathrm{a}_{\mathrm{m}}\right)^{\mathrm{T}},
$$

and where

$m=$ the number of covariates that are time-independent.

Effects of immunization accumulate with the incremental provision of vaccines as infancy progresses. The immunizations BCG, DPT1, and polio1 are optimally provided in the first six weeks of life, the DPT2 and polio2 are optimally provided in the tenth week, DPT3 and polio3 are provided in the $14^{\text {th }}$ week, and the provision of measles vaccine is optimally provided at nine months. Corresponding effects are posited to accumulate with age $t$, starting with the baseline failure rate given by the Weibull underlying hazard, with "shape parameter" $\beta$ :

$$
\lambda_{0}=\frac{\beta}{\eta}\left(\frac{t}{\eta}\right)^{\beta-1}
$$

and the conditional hazard given by

$$
\lambda(t, X)=\beta t^{\beta-1} e^{\sum_{j=0}^{m} a_{j} \cdot x_{j}}
$$

The estimation of the shape parameter $\beta$ and the vector of regression effects, $\underline{\alpha}$, obtained by the method of maximum likelihood (Therneau and Grambsch 2000), are appropriate for specifying the familiar nonlinear relationship of survival with the advancing months of age of childhood. 


\section{RESULTS}

Hazard ratios presented in Table 2 assess the gross effects of a dose of each vaccine on the hazards of mortality before the age of five. All vaccines exhibit large and statistically significant effects on child mortality. Gross effects are similar, irrespective of vaccine, owing to the intercorrelation of immunizations. Administration of each vaccine is associated with the provision of other vaccines in the immunization regimen. Although some research findings suggest that partial DPT immunization may cause more harm than good (Kristensen et al. 2000), results from Navrongo provide evidence that partial immunization by DPT and polio reduces relative risk by 57 percent.

Table 3 extends the analysis to the multivariate specification with vaccine exposure combined into "full" versus "partial" versus "none". Model I examines the effects of relative poverty and maternal educational attainment on the risk of dying among children younger than five, controlling for the effect of maternal age. Results show that successive quintiles of increasing wealth are associated with monotonically declining mortality risks. Moreover, adding a year of maternal education is associated with reduced relative risk. Clearly, relationships portrayed by the effects of poverty and maternal education in Navrongo are consistent with findings reported from elsewhere in Africa.

Model II tests the hypothesis that immunization offsets the effect of poverty and low maternal educational attainment on child mortality. Results show that introducing immunization into the model is associated with the disappearance of relative mortality effects among all but the most prosperous quintile, suggesting that only children of the most prosperous households benefit from family wealth once immunization status is included as a covariate. The relative magnitude of immunization effects versus poverty effects indicates that immunization has a much greater impact on survival than relative poverty. The risk of dying for children younger than five is reduced by more than 70 percent among those who are fully immunized, compared with those who are not. Partial immunization also prevents mortality.

The relative advantage of children in the uppermost quintile is offset by both partial and full immunization, an interaction that is further demonstrated by Model III, which introduces interactions for the joint effects of poverty quintiles and immunization status. Main effects and interactions suggest that the impact of immunization is greater among the relatively poor than the less poor and more prosperous quintiles, indicating that immunization has a leveling effect on the risks associated with poverty. This conclusion also extends to the relationship of educational attainment with survival, although this leveling effect is less dramatic owing to the metric employed to assess education effects-years of educational attainment. Adding a year of maternal education is associated with about a 3 percent reduction (1.0-0.966) in relative mortality risks when immunization is included in models, fully a percentage point less than the relative risk associated with a year of maternal education when the immunization status is excluded from the model (not shown). Although the effects of low educational attainment are offset by immunization, substantial effects remain even after immunization is included as a covariate. This finding is consistent with the possibility that educational attainment affects parental practices and health-seeking behavior, which, in turn, affect morbidity in ways that are independent of immunizable illnesses. 


\section{DisCUSSION}

The implications of the pronounced immunization effect on cumulative survival is further illustrated in Figure 4 by a Kaplan-Meier cumulative survival curve depicting the main effects of Model II childhood survival by immunization status (full, partial, or none), with statistical adjustment for maternal age and educational attainment and relative household economic status. For the purpose of the simulation, measles is included as a vaccine in the "full" and "partial" immunization categories. Thus, the Kaplan-Meier estimates combine the effects of full immunization including measles that is estimated in Model II in Table 3. The "none" curve portrays survival when no vaccine or partial immunization in the entire regimen was provided; "partial" refers to any combination of vaccines, including incomplete immunization; and "full" corresponds to the provision of all vaccines listed in Tables 1 and 2. Timing is addressed by assessing immunization status at the last time that a child was observed. Thus, "partial" and "full" immunization includes children whose immunizations were mistimed relative to the WHO-recommended regimen.

As the figure shows, children who have received all vaccinations experience substantially higher cumulative survival odds than their counterparts who are not fully immunized. Those who have received no vaccinations experience catastrophically high cumulative risks of dying by the time they reach age five in this setting, exceeding one-third of all children born. Partial immunization reduces cumulative risk to 20 percent, and full immunization leads to a further reduction of cumulative mortality risk to about 10 percent. Because the estimates portrayed in the figure are based on conditional hazard parameters that are adjusted for maternal age, educational attainment, and household poverty status, results suggest that most of the risk of dying before age five can be eliminated with full immunization in this severely health-deprived setting, which is estimated in Table 3 as a relative risk ratio of 0.084 .

Linear combinations of Model III main and interaction effects, presented in Table 4, illustrate the survival implications of childhood immunization for offsetting the effects of poverty on survival. These effects bring into account the possibility that immunization may have contrasting benefits for people at different levels of poverty. Results indicate that children from poor households benefit more from immunization than those from relatively better-off households. For example, the "none" row at the top of Table 4 shows significant improvement in survival at the most prosperous level of wealth relative to the least prosperous. The "full" row at the bottom of the table shows, however, that the pronounced effects of immunization occur equivalently across all poverty categories, corresponding to a reduction in mortality odds in excess of 90 percent relative to the odds for unvaccinated children in the poorest quintile. This equity effect may arise because immunization efforts are launched as a continuous campaign that aims to reach all children without regard for economic category, residence, or social characteristics. Moreover, immunization may have nonspecific morbidity-prevention effects that differentially benefit the nutritionally vulnerable poor (Fine 2005). Although the underlying causes of the equity effect remain unknown, Table 4 provides unmistakable evidence that children living in poverty who are immunized experience pronounced survival gains that equalize their survival odds relative to children from better-off households. 


\section{CONCLUSION}

Programs intended to address the health needs of children younger than five will require ambulatory health services to deal with the major sources of childhood morbidity and will necessitate health services that are more comprehensive than immunization alone. Nonetheless, results from this research lend strong support to the United Nations' goal of reducing excess childhood mortality among the poor by directing a particular focus on immunization. Results of this analysis also attest to the impact of the immunization program on health equity. Relative poverty has a pronounced effect on the survival of children, even in a setting where nearly all families are poor. This effect of poverty, as well as much of the effect of maternal education, is offset by immunization, lending direct empirical support to policies that promote childhood immunization as a component of poverty-reduction programs. 


\section{REFERENCES}

Aaby, Peter and Henrick Jensen. 2005. "Commentary: Contrary findings from Guinea-Bissau and Papua New Guinea.” International Journal of Epidemiology 34(1):149-151.

Adjuik, Martin, T. Smith, S. Clark, J. Todd, A. Garrib, J. Kinfu, K. Kahn, et al. 2006. "Causespecific mortality in sub-Saharan Africa and Bangladesh." Bulletin of the World Health Organization 84(3): 181-188.

Ahmad, B.A., A.D. Lopez, and M. Inoue. 2000. "The decline of child mortality: A reappraisal." Bulletin of the World Health Organization 78(10): 1,175-1,191.

Attaran, Amir. 2005. "An immeasurable crisis? A criticism of the Millennium Development Goals and why they cannot be measured." PLoS Medicine. $<$ http://medicine.plosjournals. org/perlserv/\%5C? request=get-document\&doi=10.1371/journal.pmed.0020318>. Accessed March 2006.

Bawah, A.A. and T. Zuberi. 2005. "Socioeconomic status and child mortality in southern Africa." Genus 61(2): 55-83.

Binka, Fred N., Pierre Ngom, James F. Phillips, Kubaje Adazu, and Bruce B. MacLeod. 1999. "Assessing population dynamics in a rural African society: The Navrongo Demographic Surveillance System.” Journal of Biosocial Science 31(3): 373-391.

Binka, Fred N., Ayaga A. Bawah, James F. Phillips, Abraham Hodgson, Martin Adjuik, and Bruce MacLeod. Forthcoming. "Rapid achievement of the child survival Millennium Development Goal: Evidence from the Navrongo Experiment in northern Ghana." Tropical Disease and International Health.

Black, Robert E., Saul Morris, and Jennifer Bryce. 2003. "Where and why are 10 million children dying every year?” The Lancet 361(9,376): 2,226-2,234.

Caldwell, John C. 1979. "Education as a factor in mortality decline: An example of Nigerian data. Population Studies 33(3): 395-413.

Debpuur, Cornelius, Peter Wontuo, James Akazili, and Philomena Nyarko. 2005. "Health inequities in the Kassena-Nankana District of northern Ghana." In Measuring Health Equity in Small Areas: Findings from Demographic Surveillance Systems. Eds. Don de Savigny, Cornelius Debpuur, E. Mwageni, R. Nathan, Abdur Razzaque, and Philip Setel. INDEPTH Network. Aldershot, England: Ashgate Publishing.

Desai, Sonalde and Soumya Alva. 1998. "Maternal education and child health: Is there a strong causal relationship?" Demography 35(1): 71-81. 
Filmer, D. and Lant Pritchett. 2001. "Estimating wealth effects without expenditure data or tears: An application to educational enrollments in the states of India." Demography 38(1): $115-132$.

Fine, P.E. 2005. "Non-specific effects of vaccination: Author's reply to Shann." British Medical Journal 330(April 9): 844.

Gadomski, Anne, Robert E. Black, and W. Henry Mosley. 2001. "Constraints to the potential impact of the direct interventions for child survival in developing countries." Health Transition Review Series 2, Volume 2. Pp. 729-741.

Global Alliance for Vaccines and Inmunization (GAVI). 2005. "Scaling up immunization to meet the Millennium Development Goals (MDGs)." Fact Sheet, The Vaccine Fund. Washington, DC: GAVI.

Ghana Statistical Services (GSS), Noguchi Memorial Institute for Medical Research (NMIMR), and ORC Macro. 2004. Ghana Demographic and Health Survey 2003. Calverton, MD: GSS, NMIMR, and ORC Macro.

Gwatkin, Davidson R. 2002a. "Reducing health inequalities in developing countries." In Oxford Textbook of Public Health. Eds. Roger Detels, James McEwen, Robert Beaglehole, and Heizo Tanaka. Oxford: Oxford University Press.

- 2002b. "Who would gain most from efforts to reach the Millennium Development Goals for health? An inquiry into the possibility of progress that fails to reach the poor." Health, Nutrition and Population Discussion Paper. Washington, DC: The World Bank.

Gwatkin, Davidson, Adam Wagstaff, and A.S. Yazbeck. 2005. Reaching the Poor with Health, Nutrition, and Population Services: What Works, What Doesn't, and Why. Washington, DC: World Bank Publication.

Hill, Allan. 1993. "Trends in childhood mortality." In Demographic Change in Sub-Saharan Africa. National Research Council. Washington, DC: National Academic Press. Pp.153217.

Kahn, Katherine, Mark Collinson, J. Hargreaves, Sam Clark, and Steven Tollman. 2005. "Socioeconomic status and child mortality in a rural district of South Africa." In Measuring Health Equity in Small Areas: Findings from Demographic Surveillance Systems. Eds. Don de Savigny, Cornelius Debpuur, E. Mwageni, R. Nathan, Abdur Razzaque, and Philip Setel. INDEPTH Network. Aldershot, England: Ashgate Publishing.

Kiros, Gebre-Egziabher and Dennis P. Hogan. 2001. "War, famine and excess child mortality in Africa: The role of parental education." International Journal of Epidemiology 30(3): 447-455. 
Kristensen I., P. Aabby, and H. Jensen. 2000. "Routine vaccination and child survival: Follow-up study in Guinea-Bissau, West Africa [with commentary by P. Fine]." British Medical Journal 321: 1,435-1,439.

Levine, Ruth and the What Works Working Group of the Global Health Policy Network. 2005. Millions Saved: Proven Successes in Global Health. Washington, DC: Center for Global Development.

Magnussen, Lesley, John Ehiri, and Pauline Jolly. 2004. "Comprehensive versus selective primary health care: Lessons for global health policy." Health Affairs 23(3): 167-176.

Montgomery, Mark R., M. Gragnolati, K.A Burke, and E. Paredes. 2000. "Measuring living standards with proxy variables." Demography 37(2): 155-174.

Muhuri, Pradip K. 1995. "Health programs, maternal education, and differential child mortality in Matlab, Bangladesh." Population and Development Review 21(4): 813-834.

Nathan, R., J. Armstrong-Schellenberg, H. Masanja, S. Charles, O. Mukasa, and H. Mshinda. 2005. "Child health inequity in rural Tanzania: Can the National Millennium Development Goals include the poorest?" In Measuring Health Equity in Small Areas: Findings from Demographic Surveillance Systems. Eds. Don de Savigny, Cornelius Debpuur, E. Mwageni, R. Nathan, Abdul Razzaque and P. Setel. INDEPTH Network. Aldershot, England: Ashgate Publishing.

Nyarko, Philomena, Brian Pence, and Cornelius Debpuur. 2001. "Immunization status and child survival in rural Ghana." Policy Research Division Working Paper No. 147. New York: Population Council.

Phillips, James F., Ayaga A. Bawah, and Fred N. Binka. Forthcoming. "Accelerating reproductive and child health programme impact: The Navrongo Experiment in Ghana." Bulletin of the World Health Organization.

Sachs, J.D. and J.W. MacArthur. 2005. "The Millennium Project: A plan for meeting the Millennium Development Goals." <http://image.thelance.com.extras/04artweb.pdf $>$. Accessed February 2006.

Sahn, David E. and David C. Stifel. 2003. "Progress toward the Millennium Development Goals in Africa." World Development 31(1): 23-52.

Therneau, T.M. and P.M. Grambsch. 2000. Modeling Survival Data: Extending the Cox Model. New York: Springer.

Timaeus, I.M. 1997a. "Age pattern of mortality in sub-Saharan Africa: An initial study of the impact of AIDS." Paper presented at the Annual Meetings of the Population Association of America, Washington, DC, 28-30 March. 
1997b. "Mortality in sub-Saharan Africa." Paper presented at the International Union for the Scientific Study of Population Symposium on Health and Mortality. ESA/POP/ 1997/SYMP.1/6.1. Brussels, 19-22 November. Unpublished.

- 1999. "Adult mortality in Africa in the era of AIDS." In The African Population in the $21^{\text {st }}$ Century. Third African Population Conference, UAPS-NPU, Volume 2. Dakar, Senegal: Union for African Population Studies. Pp. 377-395.

United Nations 2005a. The Millennium Development Goals Report 2005. New York: UN.

- 2005b. "World and Regional Trends." Millennium Indicators Database, <http:// millenniumindicators.un.org>. Accessed July 2005.

—. 2005c. "Progress towards the Millennium Development Goals, 1990-2005." Department of Economic and Social Statistics, Statistics Division, United Nations. $<$ http://unstats.un.org/unsd/mi/goals_2005/goal_4.pdf>. Accessed 22 November 2006.

_. 2006. The Millennium Development Goals Report 2006. New York: UN.

VAST Study Team.1993. "Vitamin A supplementation in northern Ghana: Effects on clinic attendances, hospital admissions, and child mortality." Lancet 342 (8,870): 549.

Victora, Cesar, Adam Wagstaff, Joanna Armstrong-Schellenberg, Davidson Gwatkin, Miriam Claeson, and Jean-Pierre Habicht. 2003. "Applying an equity lens to child health and mortality: More of the same is not enough." The Lancet 362(9,379): 233-244.

Wagstaff, Adam. 2000. "Socioeconomic inequalities in child mortality: Comparisons across nine developing countries." Bulletin of the World Health Organization 78(1): 19-29.

World Bank. 1993. World Development Report: Investing in Children. New York: Oxford University Press

- 2005. Improving Health, Nutrition and Population Outcomes in Sub-Saharan Africa: The Role of the World Bank, Washington, DC: The World Bank.

World Heath Organization (WHO)/AFRO. 1994. "EPI in the Africa Region in the 1990s." EPI/GAG.93/WP.2. Geneva: WHO.

World Heath Organization (WHO) Department of Vaccines and Biologicals. 2001. WHO Vaccines for Preventable Diseases: Monitoring System. Geneva: WHO. 
Table 1 Status of immunization for eight vaccines, by age of child, Kassena-Nankana District, Ghana, 1998-2004

\begin{tabular}{lclll}
\hline & \multicolumn{4}{c}{ Age of child in months } \\
\cline { 2 - 5 } Vaccine & $\mathbf{0 - 1 1}$ & $\mathbf{1 2 - 2 3}$ & $\mathbf{2 4 - 5 9}$ & All ages \\
\hline BCG & 56.81 & 81.46 & 83.96 & 75.75 \\
Polio1 & 54.74 & 82.64 & 85.75 & 76.31 \\
Polio2 & 43.54 & 80.26 & 83.48 & 71.52 \\
Polio3 & 33.39 & 75.64 & 79.13 & 65.49 \\
DPT1 & 46.88 & 81.20 & 85.51 & 73.64 \\
DPT2 & 38.51 & 78.73 & 82.88 & 69.45 \\
DPT3 & 28.98 & 74.72 & 78.64 & 63.79 \\
Measles & 4.64 & 63.93 & 72.92 & 51.60 \\
Children (N) & $(5,124)$ & $(4,655)$ & $(8,590)$ & $(18,369)$ \\
\hline
\end{tabular}

Table 2 Univariate time-conditional hazard ratios for the impact of eight vaccines on mortality among children younger than five, Kassena-Nankana District, Ghana

\begin{tabular}{ll}
\hline Vaccine & Hazard ratio (confidence intervals) \\
\hline BCG & $0.185(0.169-0.202)^{* * *}$ \\
Polio1 & $0.160(0.150-0.179)^{* * *}$ \\
Polio2 & $0.147(0.135-0.162)^{* * *}$ \\
Polio3 & $0.155(0.142-0.171)^{* * *}$ \\
DPT1 & $0.149(0.136-0.163)^{* * *}$ \\
DPT 2 & $0.145(0.132-0.159)^{* * *}$ \\
DPT 3 & $0.148(0.134-0.163)^{* * *}$ \\
Measles & $0.145(0.130-0.162)^{* * *}$ \\
\hline
\end{tabular}

$* * *$ Significant at $\mathrm{p} \leq 0.001$. 
Table 3 Time-conditional hazard ratios for the impact of immunization and poverty, maternal education, and maternal age on mortality among children younger than five, Kassena-Nankana District

\begin{tabular}{|c|c|c|c|}
\hline \multirow[b]{2}{*}{ Variable } & \multicolumn{3}{|c|}{ Hazard ratios (confidence intervals) } \\
\hline & Model I & Model II & Model III \\
\hline Mother's age & $0.955(0.920-0.992)^{*}$ & $0.977(0.942-1.055)$ & $0.978(0.943-1.014)$ \\
\hline Mother's age squared & $1.000(1.000-1.001)^{*}$ & $1.000(0.999-1.000)$ & $0.100(0.999-1.000)$ \\
\hline Mother's education & $0.958(0.941-0.976)^{* *}$ & $0.966(0.948-0.984)^{* * *}$ & $0.966(0.948-0.885)^{* * *}$ \\
\hline \multicolumn{4}{|l|}{ Poverty status } \\
\hline \multicolumn{4}{|l|}{ First quintile (poorest) } \\
\hline (r) & 1.00 & 1.00 & 1.00 \\
\hline Second quintile & $0.897(0.786-1.024)$ & $0.969(0.849-1.106)$ & $0.823(0.685-0.988)^{*}$ \\
\hline Third quintile & $0.844(0.739-0.965)^{*}$ & $0.994(0.870-1.136)$ & $0.973(0.813-1.165)$ \\
\hline Fourth quintile & $0.802(0.698-0.920)^{* *}$ & $0.919(0.800-1.055)$ & $0.723(0.595-0.881)^{* *}$ \\
\hline $\begin{array}{l}\text { Fifth quintile } \\
\text { (most prosperous) }\end{array}$ & $0.733(0.630-0.852)^{* * *}$ & $0.854(0.734-0.994)^{*}$ & $0.672(0.543-0.831)^{* * *}$ \\
\hline \multicolumn{4}{|l|}{ Immunization status } \\
\hline None $(r)$ & & 1.00 & 1.00 \\
\hline Partial & & $0.327(0.294-0.364) * * *$ & $0.245(0.198-0.305)^{* * *}$ \\
\hline Full & & $0.103(0.092-0.115)^{* * *}$ & $0.084(0.066-0.108)^{* * *}$ \\
\hline \multicolumn{4}{|c|}{ Poverty-immunization interactions } \\
\hline First·partial (r) & & & 1.00 \\
\hline Second $\cdot$ partial & & & $1.494(1.094-2.039)^{*}$ \\
\hline Third $\cdot$ partial & & & $0.941(0.673-1.316)$ \\
\hline Fourth·partial & & & $1.964(1.423-2.711) * * *$ \\
\hline Fifth·partial & & & $1.724(1.213-2.449)^{* *}$ \\
\hline First·full (r) & & & 1.00 \\
\hline Second $\cdot$ full & & & $1.310(0.925-1.856)$ \\
\hline Third·full & & & $1.158(0.826-1.623)$ \\
\hline Fourth·full & & & $1.292(0.901-1.853)$ \\
\hline Fifth·full & & & $1.510(1.048-2.175)^{*}$ \\
\hline Failures (N) & $(1,965)$ & $(1,965)$ & $(1,965)$ \\
\hline Subjects (N) & $(17,967)$ & $(17,967)$ & $(17,967)$ \\
\hline Time at risk (months) & 31346.63 & 31346.63 & 31346.63 \\
\hline Overall p-value & 0.000 & 0.000 & 0.000 \\
\hline
\end{tabular}

*Significant at $\mathrm{p} \leq 0.05 ; * * \mathrm{p} \leq 0.01 ;{ }^{* * *} \mathrm{p} \leq 0.001$. (r) = Reference category. 
Table 4 Childhood-mortality hazard ratios for linear combinations of Model III main effects and interactions of poverty quintiles with immunization status, Kassena-Nankana District, Ghana

\begin{tabular}{|c|c|c|c|c|c|}
\hline $\begin{array}{l}\text { Immunization } \\
\text { status }\end{array}$ & I (poorest) & II & III & IV & V (most prosperous) \\
\hline None & $1.00(\mathrm{r})$ & $0.823(0.685-0.988)^{*}$ & $0.973(0.813-1.165)$ & $0.723(0.595-0.881)^{* *}$ & $0.672(0.543-0.831)^{* * *}$ \\
\hline Partial & $0.245(0.198-0.305)^{* * *}$ & $0.302(0.244-0.373)^{* * *}$ & $0.225(0.175-0.288)^{* * *}$ & $0.349(0.281-0.434)^{* * *}$ & $0.284(0.221-0.366)^{* * *}$ \\
\hline Full & $0.084(0.066-0.108)^{* * *}$ & $0.091(0.072-0.114)^{* * *}$ & $0.095(0.076-0.118)^{* * *}$ & $0.079(0.062-0.100)^{* * *}$ & $0.085(0.011-0.109)^{* * *}$ \\
\hline
\end{tabular}

*Significant at $\mathrm{p} \leq 0.05 ; * * \mathrm{p} \leq 0.01 ; * * * \mathrm{p} \leq 0.001$. (r) $=$ Reference category. 
Figure 1 Kassena-Nankana District (KND) and Navrongo Health Research Project in relation to the ten regions of Ghana

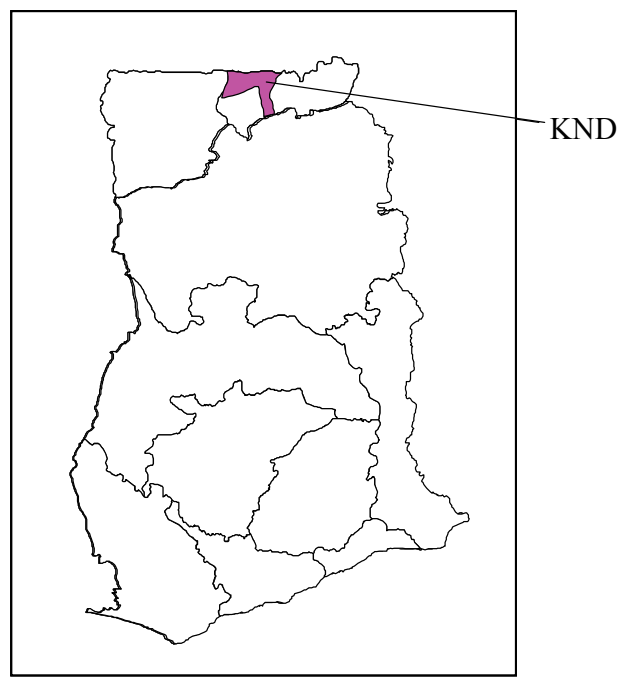


Figure 2: Infant and child mortality rates for children aged 0-59 months, Kassena-Nankana District

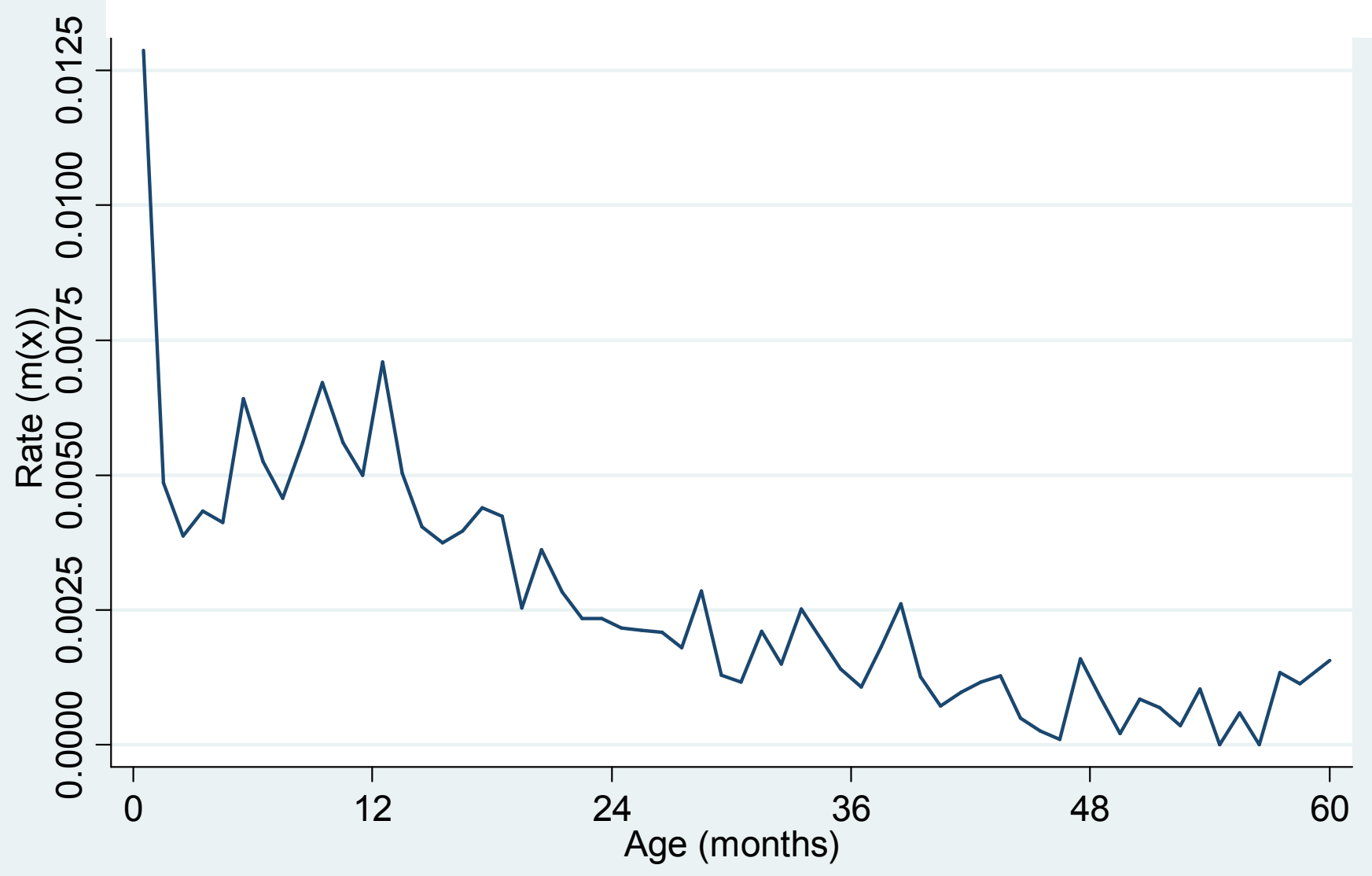




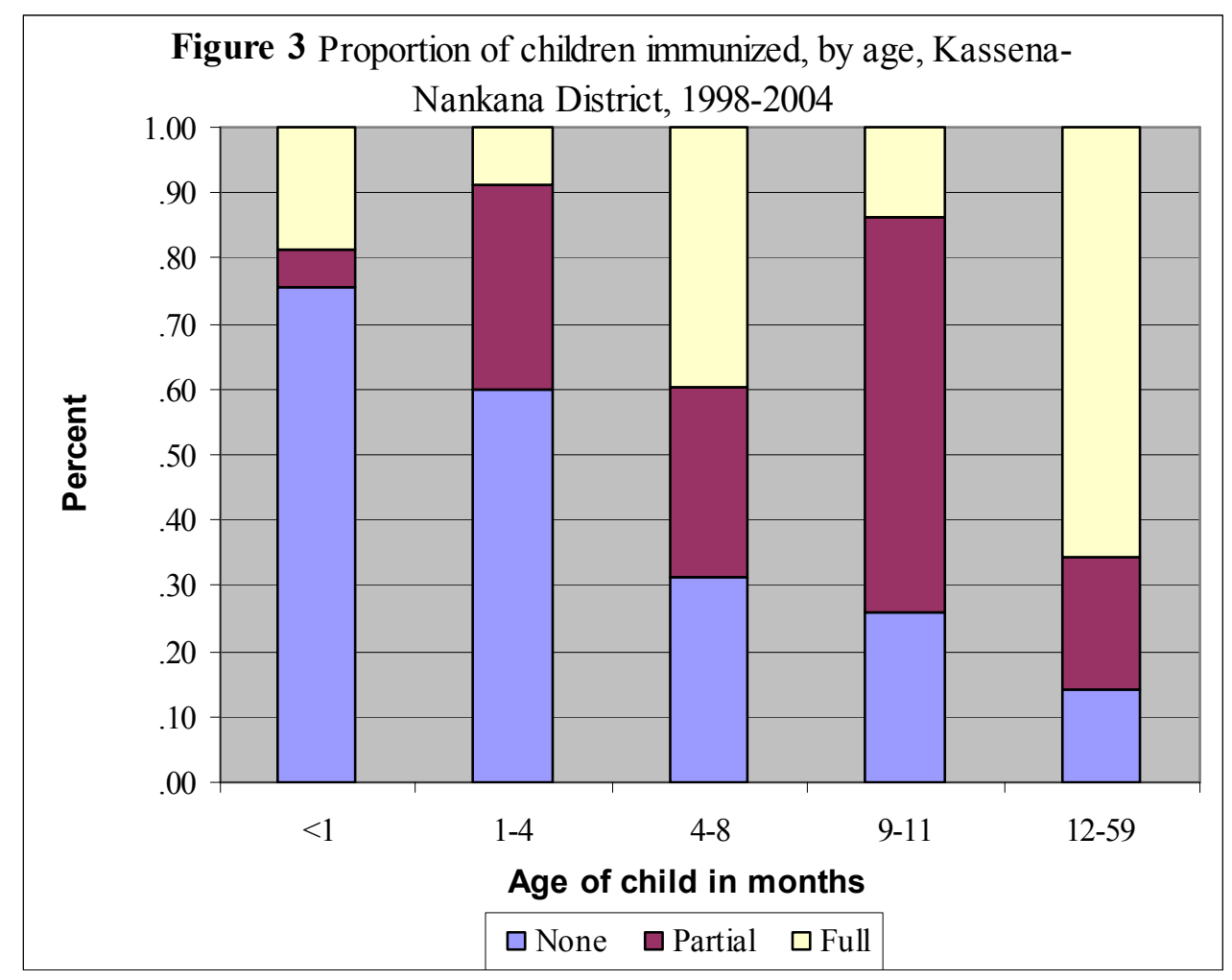


Figure 4 Kaplan-Meier cumulative probabilities of survival, by immunization status of children younger than five

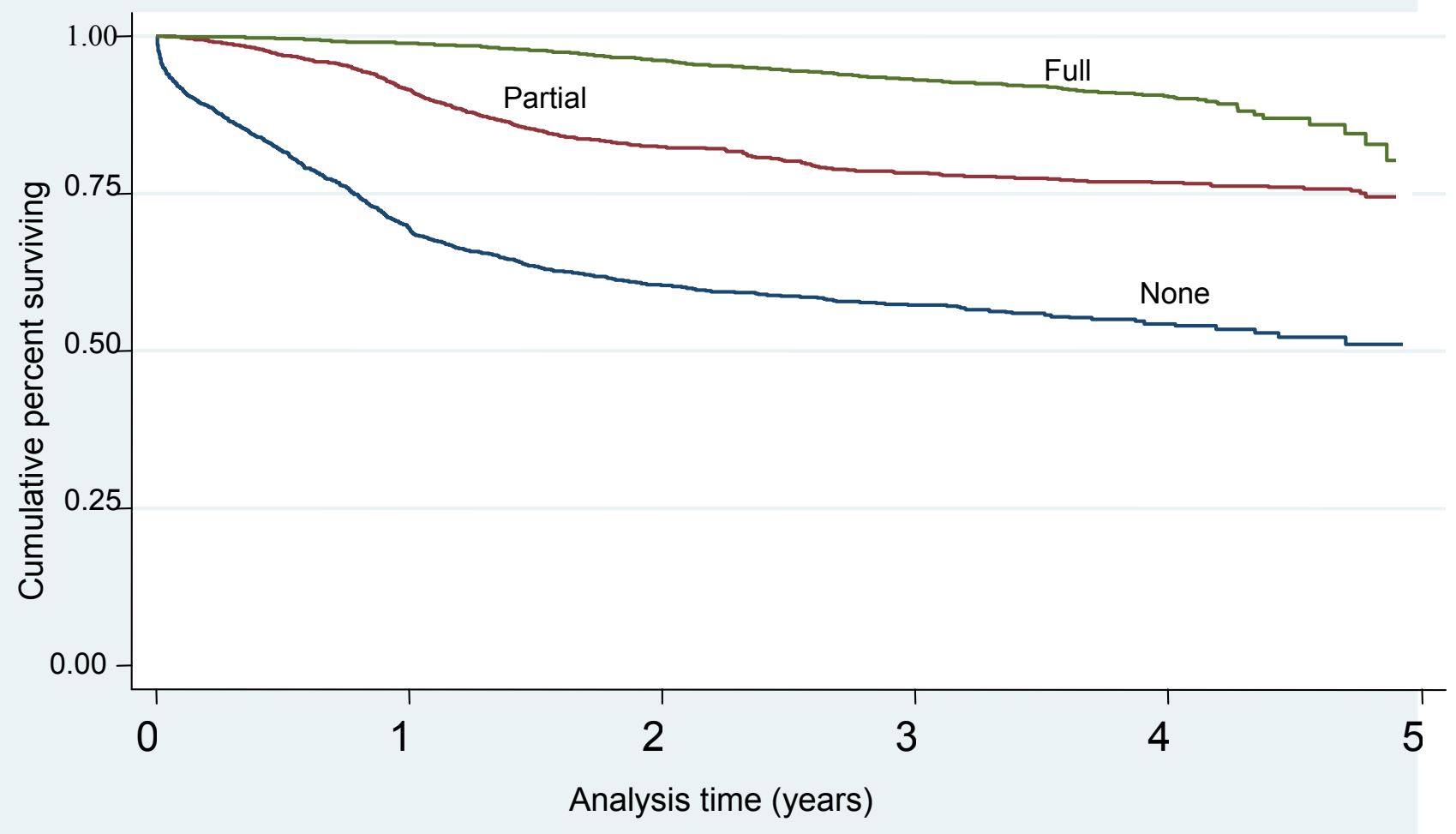




\section{POLICY RESEARCH DIVISION WORKING PAPERS}

If still in print, single copies of up to three working papers from 1989 through 2003 are available free of charge.

Beginning with the 2004 issues, working papers are no longer available in print format. Instead they are distributed electronically. As each new paper is completed subscribers are notified by e-mail and a link to the paper is provided.

To subscribe to the Policy Research Division working paper e-mail notification list, or to obtain back issues from 1989 to 2003, please send your request to prdwp@popcouncil.org.

PDFs of recent issues are available at www.popcouncil.org/publications/wp/prd/rdwplist.html

2006

218 Ayaga A. Bawah, James F. Phillips, Martin Adjuik, Maya Vaughan-Smith, Bruce MacLeod, and Fred N. Binka, "The impact of immunization on the association between poverty and child survival: Evidence from KassenaNankana District of northern Ghana."

217 Zachary Zimmer, "Poverty, wealth inequality, and health among older adults in rural Cambodia."

216 John Bongaarts, "Late marriage and the HIV epidemic in subSaharan Africa."

215 John Bongaarts, "How long will we live?"

214 Zachary Zimmer, Toshiko Kaneda, and Laura Spess, "Urban versus rural mortality among older adults in China."

213 Paul Demeny and Geoffrey McNicoll, "The political demography of the world system, 2000-2050."
212 Monica Grant and Kelly Hallman, "Pregnancy-related school dropout and prior school performance in South Africa."

211 Kelly Hallman, Sara Peracca, Jennifer Catino, and Marta Julia Ruiz, "Multiple disadvantages of Mayan females: The effect of gender, ethnicity, poverty, and residence on education in Guatemala."

210 Geoffrey McNicoll, "Policy lessons of the East Asian demographic transition."

209 Cynthia B. Lloyd, Cem Mete, and Monica J. Grant, "The implications of changing educational and family circumstances for children's grade progression in rural Pakistan: 1997-2004."

2005

208 James F. Phillips, Ayaga A. Bawah, and Fred N. Binka, "Accelerating reproductive and child health program development: The Navrongo Initiative in Ghana." 
207 John Bongaarts and Griffith

Feeney, "The quantum and tempo of life-cycle events."

206 Barbara S. Mensch, Monica J. Grant, and Ann K. Blanc, "The changing context of sexual initiation in sub-Saharan Africa."

205 Geoffrey McNicoll, "Population and sustainability."

204 John Bongaarts, "The causes of stalling fertility transitions."

203 Ayaga A. Bawah and Fred N. Binka, "How many years of life could be saved if malaria were eliminated from a hyperendemic area of northern Ghana?"

202 Barbara S. Mensch, Susheela Singh, and John B. Casterline, "Trends in the timing of first marriage among men and women in the developing world."

201 Zachary Zimmer, "Active life expectancy and functional limitations among older Cambodians: Results from a 2004 survey."

200 Brian Wells Pence, Philomena Nyarko, James F. Phillips, and Cornelius Debpuur, "The effect of community nurses and health volunteers on child mortality: The Navrongo Community Health and Family Planning Project."

199 Zachary Zimmer, Linda G. Martin, Mary Beth Ofstedal, and Yi-Li Chuang, "Education of adult children and mortality of their elderly parents in Taiwan."

198 Mian Bazle Hossain, James F. Phillips, and Thomas K. LeGrand, "The impact of childhood mortality on fertility in six rural thanas of Bangladesh."
197 Kristine R. Baker, Mary Beth Ofstedal, Zachary Zimmer, Zhe Tang, and Yi-Li Chuang, "Reciprocal effects of health and economic well-being among older adults in Taiwan and Beijing."

196 Mark R. Montgomery and Paul C. Hewett, "Poverty and children's schooling in urban and rural Senegal."

2004

195 Luciana Suran, Sajeda Amin, Lopita Huq, and Kobita Chowdury, "Does dowry improve life for brides? A test of the bequest theory of dowry in rural Bangadesh."

194 Barbara S. Mensch, Monica J. Grant, Mary P. Sebastian, Paul C. Hewett, and Dale Huntington. "The effect of a livelihoods intervention in an urban slum in India: Do vocational counseling and training alter the attitudes and behavior of adolescent girls?"

193 Amanda Ritchie, Cynthia B. Lloyd, and Monica Grant. "Gender differences in time use among adolescents in developing countries: Implications of rising school enrollment rates."

192 John Bongaarts. "Long-range trends in adult mortality: Models and projection methods."

191 John Koku Awoonor-Williams, Ellie S. Feinglass, Rachel Tobey, Maya N. Vaughan-Smith, Frank K. Nyonator, Tanya C. Jones, and James F. Phillips, "Bridging the gap between evidence-based innovation and national healthsector reform in Ghana." 
190 Kelly Hallman, "Socioeconomic disadvantage and unsafe sexual behaviors among young women and men in South Africa."

189 Toshiko Kaneda, Zachary Zimmer, and Zhe Tang, "Differentials in life expectancy and active life expectancy by socioeconomic status among older adults in Beijing."

188 Cynthia B. Lloyd and Monica J. Grant, "Growing up in Pakistan: The separate experiences of males and females."

187 Zachary Zimmer, Xianghua Fang, Toshiko Kaneda, Zhe Tang, and Julia Kwong. "Trends and transitions in children's coresidence with older adults in Beijing municipality."
186 Sajeda Amin and Alaka M. Basu. "Popular perceptions of emerging influences on mortality and longevity in Bangladesh and West Bengal."

185 John Bongaarts. "Population aging and the rising cost of public pensions."

184 Mark R. Montgomery and Paul C. Hewett. "Urban poverty and health in developing countries: Household and neighborhood effects." 